\title{
DESERTIFICAÇÃO E SEUS EFEITOS NA VEGETAÇÃO E SOLOS DO CARIRI PARAIBANO
}

\author{
Prof. Dr. Bartolomeu Israel de Souza \\ Programa de Pós-Graduação em Geografia da UFPB \\ Rua Major Salustiano Ribeiro, nº 125, aptº 802, Edifício Res. Sândalos, CEP: 58039-050, João Pessoa/PB - Brasil \\ Telefone: (83)3216-7595 - bartoisrael@yahoo.com.br \\ Prof ${ }^{a}$ Dr $^{\mathrm{a}}$ Dirce Maria Antunes Suertegaray \\ suerte.ez@terra.com.br \\ Prof. Dr. Eduardo Rodrigues Viana de Lima \\ eduvianalima@gmail.com
}

\begin{abstract}
RESUMO
A desertificação é a degradação das terras nas zonas secas do mundo, tendo como causas tanto a ação do clima como as atividades humanas. No Brasil, a região do Cariri paraibano, além das fortes estiagens a que está submetida, tem sido palco de um processo secular de desertificação, atingindo principalmente as caatingas existentes, o que compromete atualmente a maior parte do seu território. Os solos, a exceção de algumas áreas submetidas a irrigação, a despeito das modificações intensas que tem ocorrido na cobertura vegetal, devido as suas características naturais e elevada presença de Pavimento Desértico, permanecem com os níveis de fertilidade química sem grandes alterações, embora aspectos relacionados as modificações da sua temperatura, em virtude do desmatamento intenso, e os efeitos desse processo na vegetação, devam ser levados em consideração ao se pensar numa regeneração espontânea das caatingas e o uso dessas terras para empreendimentos agropecuários.
\end{abstract}

Palavras-chave: Desertificação, Cariris Velhos, Desmatamento, Solos.

\begin{abstract}
Desertification is the degradation of lands in worldwide dry areas, having the climate influence and human activities as main causes. In Brazil, the cariri region in Paraiba, besides the strong shortages periods which it is submitted, has become the scene of a heavy process of desertification, reaching principally the existing caatingas, currently compromising the largest part of its territory. Despite of their natural characteristics and a high presence of desert areas, the soils, except for some areas submitted to irrigation, have remained at the levels of chemical fertility without great amendments. However aspects related to changes in the temperature of these soils, due to intense deforestation, and the effects of the process in the vegetation, should be taken into consideration when thinking about a spontaneous regeneration of the caatingas and the use of these lands as agriculture and farming ventures.
\end{abstract}

Keywords: Desertification, Old Cariris, Deforestation, Soils.

\section{RESUMEN}

La desertificación es la degradación de las tierras em las zonas sequias del mundo, tenendo como causas tanto el acción del clima como las actividades humanas. En el Brasil, en la región del Cariri paraibano, además de las fuertes estiajes a las quales está sumetida, tiene sido palco de um proceso secular de desertificación, atingindo principalmente las caatingas existentes, comprometendo atualmente gran parte de su território. Los suelos, a excepción de algunas áreas sumetidas a irrigación, no obstante las modificaciones intensas que han ocurrido em la cubierta vegetal, devido a sus características naturales y presencia de Pavimiento Desértico, permanecen con los niveles de fertilidad química sin grandes alteraciones, aunque aspectos relacionados a las modificaciones de su temperatura, em virtude de la retirada intensa de la vegetación, devan ser llevados em consideración para se pensar en una regeneración espontánea de las caatingas y el uso de esas tierras para proyectos agropecuários.

Palabras Clave: Desertificación, Cariris Velhos, Desmatamiento, Suelos.

\section{Introdução}

A palavra desertificação é de origem latina, sendo uma derivação de desertus e fixação. A primeira apresenta duplo significado. Como adjetivo, pode ser traduzido para desabitado, abandonado, inculto, selvagem. Como substantivo quer dizer solidão, desolação, área vazia. A segunda é um sufixo verbal 
proveniente do verbo ficare, significando ação de fazer, ser feito, ser produzido (Tavares de Melo, 1998). Apesar da etimologia original dos termos que formam essa palavra, notadamente a partir da década de 1970, esta passa a expressar um conjunto de processos que dão origem a áreas degradadas nas regiões de clima seco (Mainguet, 1995).

Atualmente os dados conhecidos sobre a desertificação revelam a gravidade desse problema de escala mundial já que, conforme Roxo (2006), entre outras características:

- afeta direta e indiretamente mais de 1 bilhão de pessoas;

- mais de 100 países sofrem com esse processo;

- são perdidos cerca de seis milhões de hectares de terra arável e produtiva todos os anos em função desse tipo de degradação;

- cerca de 1/4 da superfície terrestre sofre de degradação e erosão dos solos advindas da desertificação;

- o solo arável por pessoa diminuiu de 0,32ha., em 1961-62, para 0,21ha. em 1997-99, esperandose que diminua para 0,16 ha. em 2030.

No início da década de 1990 esse conjunto de processos é definido oficialmente como "[...] a degradação da terra nas zonas áridas, semi-áridas e sub-úmidas secas, resultante de vários factores, incluindo as variações climáticas e as actividades humanas." (CONVENÇÃO DAS NAÇÕES UNIDAS DE COMBATE Á DESERTIFICAÇÃO, 1995, p. 13). Por essa definição, sua origem está relacionada tanto a causas naturais como aquelas derivadas da pressão exercida pelas atividades humanas em ecossistemas frágeis, o que conduziria determinadas áreas a se transformarem em desertos ou a eles se assemelharem (Conti, 1995).

Enquanto a palavra desertificação se consolidava internacionalmente como um tipo de degradação, a região do Cariri paraibano (também conhecida como Cariri ou Cariris Velhos), desde o início dos estudos sobre essa temática no Brasil, na década de 1970, através dos trabalhos do professor João Vasconcelos Sobrinho, da Universidade Federal de Pernambuco (UFPE), ficava conhecida como uma das expressões territoriais onde a manifestação desse conjunto de processos seria das mais intensas.

Mesmo que essa parte da Paraíba tenha chamado atenção desde que as discussões sobre a desertificação foram iniciadas no Brasil, somente a partir da década de 1990 esse problema começou a ser pesquisado de forma mais direcionada à região. Ainda assim, os trabalhos existentes sobre a desertificação no Cariri, até agora, são muito poucos. Dentre esses, destacaríamos os de Gomes da Silva (1993), Souza (1999), Moura (2002), Silva (2003a), Souza \& Suertegaray (2005 e 2006), Pereira (2006), Andrade et al. (2007), Souza \& Lima (2007), Sousa (2007) e Souza (2008).

Em relação aos trabalhos dos autores supracitados, observamos que as abordagens desenvolvidas apresentam uma relativa diversificação, embora a maioria desses enfatize a vegetação e as suas alterações como elemento básico para se compreender esse tipo de degradação e, em alguns casos, espacializar esse processo.

Como o conceito de desertificação nos encaminha para a degradação das terras nas zonas de clima seco e a retirada da vegetação é a ação mais comum que pode desencadear esse processo, espera-se que algumas das suas conseqüências mais sérias estejam relacionadas aos solos das regiões afetadas, em decorrência do aumento da erosão e os seus efeitos na fertilidade.

Ocorre que nos trabalhos que tem abordado a desertificação no Cariri com base no desmatamento, quase sempre se faz menção a erosão e a conseqüente perda ou diminuição da fertilidade dos solos nas áreas consideradas degradadas, embora, a exceção de Souza (2008), não se apresente nenhuma análise laboratorial que comprove essa observação.

Pretende-se assim, como objetivo geral desse artigo, identificar o processo de desertificação no Cariri, associando esse tipo de degradação aos usos dos solos, especificamente os que dizem respeito às alterações empreendidas nas caatingas, uma vez que este é um dos principais parâmetros utilizados nos 
estudos voltados para esta temática, bem como a influência dessas ações nas características pedológicas de fertilidade e salinidade originais.

Os procedimentos metodológicos adotados para o desenvolvimento desse trabalho foram baseados na leitura de uma bibliografia que versou sobre o processo histórico de ocupação das terras do Cariri e as paisagens vegetais originais encontradas nessa região, a observação em campo de parâmetros das caatingas que pudessem demonstrar a presença da desertificação (estratos, densidade e diversidade) e a análise de amostras de solos para serem determinados os níveis de salinidade e fertilidade existentes.

\section{A região estudada: características gerais e fragilidade perante a desertificação}

O Cariri encontra-se localizado no centro-sul do estado da Paraíba, distanciando-se de 180 a pouco mais de 300km de João Pessoa (capital), perfazendo um vasto território com área de $11.192,01 \mathrm{~km}^{2}$, o que equivale a pouco mais de $20 \%$ do estado em questão (figura 1 ).

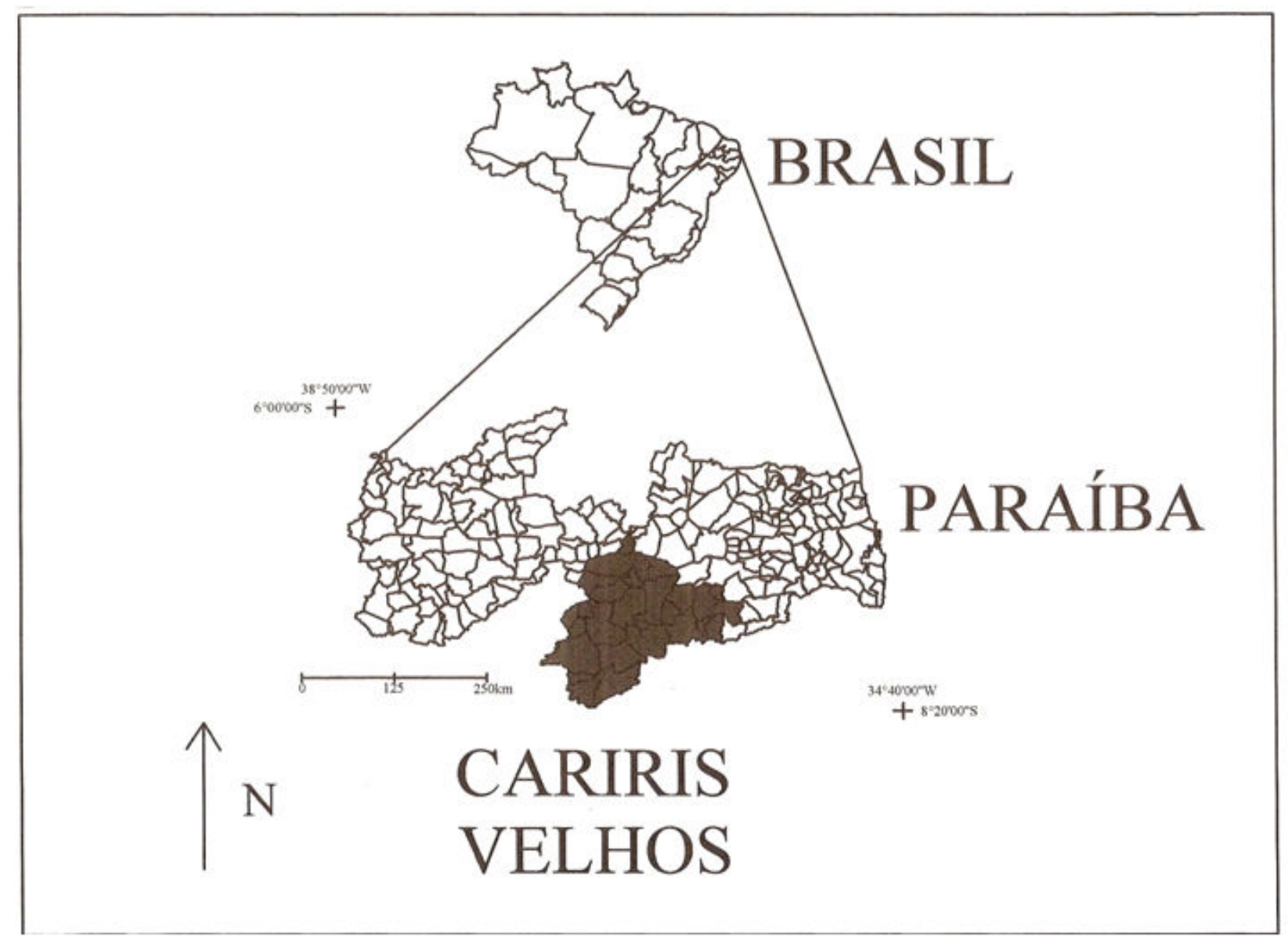

Figura 1- Localização dos Cariris Velhos na Paraíba.

Embora no estado do Ceará exista uma outra região também conhecida como Cariri, as diferenças entre essas duas são marcantes pois, enquanto na Paraíba esta se constitui num conjunto de terras de seca extrema, no estado vizinho domina uma umidade relativamente elevada para os padrões do interior nordestino. 
Além dessa diferença climática, também o processo histórico de ocupação foi relativamente distinto, sendo mais antigo no Cariri paraibano, ou seja, durante o processo de catequização, expulsão ou extermínio dos índios que existiam nessas terras, muitas tribos remanescentes buscaram refúgio no Cariri cearense. Por conta disso, o Cariri paraibano é conhecido também pelo nome de Cariris Velhos, enquanto no Ceará é denominada de Cariris Novos.

Os elementos comuns do conjunto de paisagens existentes nos Cariris Velhos são os baixos índices pluviométricos, as temperaturas médias elevadas (cerca de $27^{\circ} \mathrm{C}$ ), o déficit hídrico acentuado, a caatinga hiperxerófila, as limitações edáficas (solos rasos e, em muitos casos, com altos teores de salinidade), cidades pequenas e baixa densidade demográfica.

Do ponto de vista geomorfológico, os processos erosivos que atuaram nos Cariris Velhos, determinando as suas formas de relevo, proporcionaram a elaboração de extensas superfícies aplainadas presentes na área central do Planalto da Borborema, decorrentes de fases climáticas, ora mais xéricas ora menos xéricas, resultando na criação de amplos pediplanos. Atualmente essas superfícies estão submetidas a um princípio de dissecação predominantemente em interflúvios tabulares, com ocorrência ocasional de alinhamentos de cristas, inselbergs e amontoados de caos de blocos (BRASIL, 1981).

Tomado em seu conjunto, o Planalto da Borborema nessa região caracteriza-se pelo predomínio de um relevo semi-colinoso. Entretanto, em sua porção sudeste, esse planalto encontra-se muito dissecado pelos formadores da bacia hidrográfica do rio Paraíba (Carvalho, 1982), formando uma depressão intermontana $(250 \mathrm{~m})$, num vale estreito e encaixado, margeando as linhas de serras no limite com Pernambuco, podendo essas chegarem a $1.180 \mathrm{~m}$, embora a altitude média da região esteja situada na faixa dos 450-500m.

Quanto ao aspecto climático, este é o elemento natural que mais chama atenção no Cariri, destacandose, particularmente, a pequena quantidade de chuvas que ocorre na região, o que acaba influenciando o processo de desertificação que vem se estabelecendo em seu território.

A localização dessa região exerce papel fundamental na compreensão dos baixos índices pluviométricos aí dominantes. O Cariri está situado no fim do percurso dos fluxos úmidos que se direcionam para o semiárido nordestino e em situação de sotavento, fazendo parte da diagonal mais seca do Brasil, com médias pluviométricas de cerca de 500mm/ano (Nimer, 1979).

Apesar dessa média, a complexidade relativa a quantidade e distribuição das chuvas nessa região é muito elevada, tanto em nível temporal como espacial. No primeiro caso, embora a maior parte das chuvas se concentre entre os meses de fevereiro e maio, mesmo nesse período a sua distribuição está longe de ser homogênea, sendo comum, por exemplo, que a pluviosidade esperada para um mês possa ocorrer em poucos dias ou mesmo horas, enquanto a chuva seguinte só venha ocorrer muitas semanas depois .

No segundo caso, relativo a distribuição espacial das chuvas, também é comum que esta se caracterize pela elevada heterogeneidade, ocorrendo que, enquanto alguns setores podem receber uma precipitação esperada ou mesmo acima da média estimada, em outras áreas as chuvas podem ficar muito aquém desse valor. Portanto, as médias pluviométricas são medidas muito distantes do que realmente acontece nessas terras.

Outro aspecto climático que chama atenção no Cariri é o seu Índice de Aridez. Para o município de São João do Cariri, por exemplo, Souza (1999) obteve o índice de 0,22. Levando-se em consideração que, nos climas áridos, o Índice de Aridez varia de 0,05 a 0,20, a proximidade do resultado obtido para o município citado em relação a essas áreas demonstra a severidade climática dessa região.

Dessa maneira, conforme observa Nimer (1980), sobre a influência das variações pluviométricas e da instabilidade climática como elementos de autodefesa ambiental e de recuperação em relação aos processos de degradação gerados pela desertificação, as características encontradas no Cariri tornam esse processo, quando existente, de difícil contenção e de elevada complexidade.

Pelo que expusemos até o momento, a presença da desertificação no Cariri é condicionada pelo domínio de um clima semi-árido que, em determinados setores, poderia mesmo ser classificado como 
árido moderado, dada a severidade com que este se manifesta, ultrapassando assim o limite relativo que separa essas duas categorias (Ab’Sáber, 1974).

Entretanto entendemos que a existência, por si só, dessas características climáticas, embora desempenhe papel importante para o processo de desertificação nessa região, não é determinante. $\mathrm{Na}$ realidade, o fator mais importante no desencadeamento desse tipo de degradação está relacionado às formas seculares com que essas terras foram e são ocupadas, conforme veremos a seguir.

\section{Cariri: características pedológicas, uso do solo e influências na vegetação}

Existe, de uma forma geral, uma relação estreita entre o processo desertificação e os solos. Neste sentido, a CONVENÇÃO DAS NAÇÕES UNIDAS DE COMBATE À DESERTIFICAÇÃO (1995) insere a questão pedológica num contexto mais amplo, relacionada a degradação da terra, entendendo esta última como

[...] a redução ou perda, nas zonas áridas, semi-áridas e sub-húmidas secas, da produtividade biológica ou econômica e da complexidade das terras agrícolas de sequeiro, das terras agrícolas de regadio, das pastagens naturais, das pastagens semeadas, das florestas ou das áreas com arvoredo disperso, devido aos sistemas de utilização das terras ou a um processo ou combinação de processos, incluindo os que resultam da actividade do homem e das suas formas de ocupação do território, tais como: (i) A erosão do solo causada pelo vento e/ou pela água; (ii) A deterioração das propriedades físicas, químicas e biológicas ou econômicas do solo e, (iii) A destruição da vegetação por períodos prolongados. (CONVENÇÃO DAS NAÇÕES UNIDAS DE COMBATE À DESERTIFICAÇÃO, 1995, p. 14).

De acordo com essa citação, é de se esperar que, em conseqüência da desertificação, os solos de uma região atingida por esse processo tenham alguns dos seus padrões originais alterados, ficando claro que a diminuição da fertilidade e o aumento da salinidade poderiam ser algumas das conseqüências desse tipo de degradação.

No Cariri paraibano há uma grande variedade pedológica, não apenas em relação às classes de solos existentes, mas também em relação às diversas associações em que estes ocorrem, conforme atestam os documentos BRASIL (1972) e PARAÍBA(1997). De forma geral, os solos encontrados nessa região são originários de rochas cristalinas, geralmente rasos, argilosos, pouco lixiviados, com predomínio de erosão laminar e fertilidade, embora variada, normalmente boa.

A disponibilidade em meio digital de um mapeamento de solos para todo o território paraibano (PARAÍBA, 1997), permitiu que identificássemos aqueles relacionados a região estudada. A seguir, baseando-se em BRASIL (1972), Sá et al. (1994), Palmieri \& Larach (1996), PARAÍBA (1997) e EMBRAPA(2006), descreveremos algumas características das classes de solos encontradas no Cariri, assim como a cobertura vegetal que, originalmente, lhes recobria:

1) Luvissolo Hipocrômico: Ocorrem nas superfícies onduladas a forte onduladas, com perfis relativamente profundos $(150$ a $250 \mathrm{~cm})$, $\mathrm{PH}$ ácido, sendo moderadamente a bem drenados. Apresentam, originalmente, cobertura vegetal densa e diversificada.

2) Luvissolo Crômico: Ocorrem em relevo suave ondulado e raramente em relevo ondulado, sendo pouco profundos ou rasos, com $\mathrm{PH}$ de baixa acidez e, em alguns casos, básico. Na superfície é comum a ocorrência de cascalhos e calhaus de quartzo (Pavimento Desértico). Tal como no tipo de solo anterior, a vegetação original é composta por um tipo de mata seca de alto porte.

3) Planossolo Háplico: Ocorrem em relevo suave ondulado, com vertentes longas de pequena declividade e vales normalmente abertos, ocupando as cotas mais baixas da região. São rasos, 
apresentando saturação por sódio, imperfeitamente drenados, com ligeiro encharcamento durante o período das chuvas e extremo ressecamento e endurecimento na época seca. Por esses motivos, são naturalmente desfavoráveis ao crescimento de plantas arbóreas, onde as caatingas caracterizamse por serem formadas por espécies pouco diversificadas, espaçadas e/ou agrupadas em pequenos bosques.

4) Planossolo Nátrico: Possuem as mesmas características que a classe de solo anterior, embora apresente maior enriquecimento em sódio, o que torna as caatingas existentes ainda mais empobrecidas.

5) Cambissolo Úmico: Ocorrem em áreas de relevo forte ondulado a montanhoso, com forte declividade. São profundos, fortemente drenados, ácidos ou moderadamente ácidos. Em relação a cobertura vegetal, esta apresenta-se originalmente densa e diversificada.

6) Vertissolo Hidromórfico: Ocorrem nas áreas de relevo suave ondulado a ondulado, em depressões com problemas de drenagem e elevada presença de argilas de alta atividade química (montmoriloníticas), o que confere a esses solos notável capacidade de dilatação, quando molhados, e contração, quando secos. Nesse processo, nas fendas abertas durante a estação seca, caem materiais da parte superficial que atingem as partes profundas do perfil, enquanto durante a estação chuvosa, devido a expansão das argilas, materiais das partes baixas do perfil são pressionados e podem ser expelidos, existindo assim um auto-revolvimento nesses solos, o que thes confere elevada fragilidade à erosão. Dessa forma, apesar de, em princípio, apresentarem cobertura vegetal relativamente densa e variada, em caso de desmatamento, ocorrem dificuldades para a sua recolonização por parte de diversas plantas, uma vez que as suas sementes, junto com algumas partículas desse tipo de solo, são arrastadas horizontalmente nesse processo sazonal de expansão/ retração. Além dessa característica, em virtude da maior deficiência de drenagem presente em algumas áreas, podem, ocasionalmente, ocorrer problemas em relação ao desenvolvimento das plantas devido ao acúmulo de sais.

7) Neossolo Flúvico: Ocorrem nas áreas de relevo plano ou com ondulações muito suaves, correspondentes as faixas estreitas ao longo dos cursos d'água, provenientes de deposições fluviais. Apresentam fertilidade natural alta, sendo pouco profundos ou profundos, moderadamente ácidos e alcalinos nas camadas inferiores, sem problemas de erosão, com drenagem moderada ou imperfeita. Originalmente eram ocupados por matas ciliares, com elevada presença de espécies de porte arbóreo, entretanto, onde a drenagem mostra-se deficiente, também podem apresentar problemas devido ao acúmulo de sais, o que desfavorece a diversidade, a densidade e o porte das plantas que colonizam esses tipos de solo.

8) Neossolo Regolítico: Ocorrem em áreas de relevo plano, suave ondulado e ondulado, sendo pouco desenvolvidos, muito arenosos, profundos e fortemente drenados. Apresentam cobertura vegetal densa e diversificada.

9) Neossolo Litólico: Ocorrem em áreas de relevo suave ondulado a montanhoso, sendo pouco desenvolvidos, muito rasos ou rasos, moderadamente ácidos, com drenagem moderada a acentuada. Apresentam rica cobertura vegetal quando isentos de uso.

10) Chernossolo Rêndzico: Ocorrem em áreas planas, sendo rasos ou muito rasos, apresentando elevados teores de carbonato de cálcio, o que lhes confere fertilidade muito elevada. A cobertura vegetal original é densa e variada.

Além dos solos acima destacados, a região do Cariri também conta com a presença de alguns Afloramentos de Rocha nas áreas de relevo forte ondulado a montanhoso, desprovidos quase por completo 
de vegetação. Embora existentes, são de pouca expressão espacial no território em questão.

A partir do mapeamento digital de solos disponível em PARAÍBA (1997), através do uso do software Spring, versão 4.2, foi efetuada a quantificação das classes de solos no Cariri, estando organizada na tabela 1, de acordo com a sua maior abrangência espacial na região.

Tabela 1- Área ocupada pelas diferentes classes de solos no Cariri.

\begin{tabular}{|l|c} 
CLASSES DE SOLOS & ÁREA OCU PADA NO CARIRI $\left(\mathbf{k m}^{\mathbf{2} / \%)}\right.$ \\
\hline Luvissolo Crômico & $4.783,7 / 42,7$ \\
Neossolo Litólico & $3.876,0 / 34,6$ \\
\hline Vertissolo Hidromórfico & $1.001,6 / 8,9$ \\
\hline Neossolo Regolítico & $460,4 / 4,1$ \\
Neossolo Flúvico & $383,9 / 3,4$ \\
Planossolo Nátrico & $265,0 / 2,4$ \\
Luvissolo Hipocrômico & $131,2 / 1,2$ \\
\hline Planossolo Háplico & $78,2 / 0,7$ \\
\hline Cambissolo Úmico & $65,7 / 0,6$ \\
Cherno ssolo Rêndzico & $27,9 / 0,2$
\end{tabular}

Pelo exposto nessa tabela, os solos das classes Luvissolo Crômico e Neossolo Litólico ocupam juntos $8.659,7 \mathrm{~km}^{2}$ de toda a região, o que equivale a 77,3\% do território em questão. A localização desses solos, em termos topográficos, é muito variável, embora estejam mais presentes nas áreas de declividade suave à moderada. Além disso, ocupam extensas áreas no entorno dos principais rios da região.

O relevo pouco declivoso sobre o qual, em grande parte, estão assentados, a presença próxima dos recursos hídricos, sua grande extensão territorial e boa fertilidade natural fizeram, historicamente, com que esses solos apresentassem elevada concentração populacional e uso antigo, o que os torna mais passíveis ao processo de desertificação.

Esse uso, por sua vez, está relacionado principalmente às atividades agropecuárias, numa estrutura fundiária que atualmente se caracteriza pelo predomínio das pequenas propriedades, onde a pequena disponibilidade de terras, associada a escassez de capital dos produtores rurais, impede a reprodução de algumas técnicas antigas de manejo dos solos, principalmente aquelas baseadas no pousio anual dos mesmos, o que acaba acarretando forte impacto que se repercute não apenas nesses elementos naturais, mas também, entre outros, na vegetação nativa.

Tentando identificar no Cariri as paisagens vegetais dominantes originalmente e, a partir daí, podermos perceber no campo o que seria atualmente uma caatinga degradada de outra preservada, recorremos à leitura de registros históricos para conhecermos o processo de ocupação da região e as modificações empreendidas nesse território. Tais documentos nos remetem a um conjunto de paisagens caracterizadas pela heterogeneidade em termos de recobrimento vegetal. Entretanto, esses mesmos documentos também nos dão idéia do predomínio de caatingas que atingiam densidades elevadas, onde dominava o estrato arbóreo (Pinto, 1977; Almeida, 1979; Nantes, 1979; Aguiar \& Ribeiro Coutinho, 1982).

Corroborando com esses registros, o conhecimento atual sobre a diversidade de espécies vegetais em algumas áreas melhor preservadas nessa região, tem demonstrado que existe um número cada vez 
mais variado de plantas, onde dominam os indivíduos arbóreos (Quirino, 2006), o que também foi identificado nos diversos trabalhos de campo que fizemos por essas terras durante o desenvolvimento desse trabalho.

Além do exposto acima, levamos em consideração o fato das caatingas serem originalmente dominadas pelo estrato arbóreo (Duque, 1980), aspecto evidenciado pelo próprio significado do nome indígena desse tipo de vegetação, ou seja, "mata branca". Tal referência nos remete a existência de um tipo de floresta de porte menos alto que as existentes nas zonas úmidas que, na maior parte do ano, se mantém desfolhada e com tonalidades próximas ao branco como estratégia de sobrevivência ao clima seco dominante.

Fazendo um paralelo entre os solos e a cobertura vegetal, cabe ressaltar ainda que, embora a presença do Bioma caatinga seja uma conseqüência direta do clima semi-árido, a diversidade de espécies, portes e densidades da vegetação, excluindo-se daí as atividades humanas como formadoras de paisagens vegetais, é determinada principalmente pela variedade de solos dominantes nessa região. Nesse caso, ainda que possam ser distintas as espécies presentes, quase todos os solos do Cariri, seguindo uma regra para todo o semi-árido nordestino, apresentam originalmente o domínio de uma vegetação do tipo florestal. A exceção nessa região ocorre nas áreas onde existem os Planossolos Háplico e Nátrico, devido a elevada ocorrência de sais que caracterizam esses solos, tornando as espécies de plantas existentes pouco variadas e com baixa densidade (Sá et al., 1994).

Por tudo o que foi exposto, consideramos que qualquer outro estrato de vegetação preponderante que não o arbóreo (com as suas variantes) é resultante de uma maior fragilidade da estrutura geo-ecológica dominante em alguns setores dessas paisagens e/ou das ações antrópicas, caracterizando, dessa forma, a presença da desertificação no Cariri.

\section{Análise dos resultados obtidos}

Para verificarmos se as atividades econômicas que vem se desenvolvendo secularmente na região têm provocado alterações em algumas características pedológicas, realizamos coletas a $10 \mathrm{~cm}$ de profundidade em vários solos dos municípios do Cariri, tendo essas ocorrido em áreas submetidas a diversas atividades agropecuárias, e também naquelas sem uso econômico, onde a vegetação em muito se assemelha ao que deveria ser no início da colonização dessas terras.

Foram coletadas 15 amostras de solos, distribuídas entre os tipos: Luvissolo Crômico e Neossolo Litólico, pela sua maior expressão territorial (perfazem juntos 77,3\% da região); Vertissolo Hidromórfico que, apesar da pouca relevância espacial (8,9\% da região), ocupa a terceira posição entre os tipos de solos de maior presença no Cariri, e Neossolo Flúvico que, embora de menor expressão territorial que o último tipo mencionado ( $3,4 \%$ da região), é muito utilizado nas atividades agrícolas.

Os resultados das análises de salinidade e fertilidade destes solos, desenvolvidas no Laboratório de Química e Fertilidade do Solo da Universidade Federal da Paraíba (campus II/Areia), podem ser visualisados na figura 2 .

Para tornar os resultados expostos na figura 2 melhor compreendidos em relação às diversas situações de uso as quais estão submetidas as variedades de solos coletadas e analisadas, elaboramos a tabela 2.

Conforme pudemos constatar na figura 2 e na tabela 2, os resultados mostraram problemas de salinidade em algumas amostras de solos das classes Neossolo Flúvico, Luvissolo Crômico e Vertissolo Hidromórfico. Embora devamos levar em conta questões relacionadas à drenagem deficiente e ao fato de, normalmente, esses solos estarem associados a outros tipos considerados salinos (Planossolos Háplico e Nátrico), o fator preponderante para esses resultados, a exceção da amostra 10460, conforme demonstra a tabela 2 , foi a presença da agricultura irrigada. 




Figura 2 - Resultados das análises de salinidade e fertilidade dos solos coletados.

Fortalecendo essa observação, nas amostras de solos coletadas nas várzeas de alguns rios da região (Neossolo Flúvico), onde a agricultura praticada para fins de subsistência não se utiliza de irrigação (amostras 9141 e 9143), a salinidade não se fez presente.

Em conversas com os proprietários das terras de onde foram retiradas as amostras, cujos solos apresentaram problemas de salinidade e onde se pratica a agricultura irrigada, o comentário dos mesmos foi de que, em parte dessas terras, a produção, principalmente de frutas, vem caindo de forma intensa, havendo diversos casos de muitas mudas de fruteiras (principalmente mamão, figo e goiaba) não se desenvolverem nesses solos. Perguntados se eles tinham conhecimento sobre as razões que estariam afetando a produção, o desconhecimento dos proprietários foi total.

Os estudos de Leprun (1981, 1988 e 1989), comparando o semi-árido brasileiro com o Sahel (África), mostram os mesmos aspectos identificados nesse trabalho em relação a questão da salinização provocada por efeito da irrigação no Cariri. Além disso, o autor citado destaca que a intensificação desse processo pode, inclusive, comprometer seriamente a fertilidade dos solos na zona de clima semi-árido da Região Nordeste do Brasil, em virtude das águas de escoamento superficial nessas terras serem mais carregadas de sais que na região africana. 
Tabela 2- Condições de salinidade e fertilidade dos solos do Cariri.

\begin{tabular}{|c|c|c|c|c|}
\hline $\begin{array}{l}\mathbf{N}^{0} \text { da } \\
\text { Amostra } \\
\text { de Solo }\end{array}$ & Classes de Solos & Uso Atual & Salin ida de & Fertilidade \\
\hline 9140 & Vertissolo Hid romórfico & Pastagem nativa (Caatinga Arbu stiva Fechada) & Ausente & Normal \\
\hline$\overline{9141}$ & Neossolo Flúvico & Agricultura de vazante (subsi stên cia) & Ausente & Normal \\
\hline 9142 & Neossolo Litólico & Pastagem nativa (Caatinga Arbu stiva aberta) & Ausente & Normal \\
\hline 9143 & Neossolo Flúvico & Agricutura de vazante (subsi stência) & Ausente & Normal \\
\hline 9144 & Neossolo Flúvico & Fruticultura irrigada (comercial) & Pres ente & Normal \\
\hline 9145 & Luvissolo Crômico & Fruticultura irrigada (comercial) & Pres ente & Normal \\
\hline$\overline{9146}$ & Luvissolo Crômico & Pastagem nativa (Caatinga Arbu stivo-arbórea fechada) & Ausente & Normal \\
\hline 10455 & Luvissolo Crômico & Área desmatada (solo exposto) & Ausente & Normal \\
\hline 10456 & Luvissolo Crômico & Área preservada (Caatinga Arbóreo-arbu stiva fechada) & Ausente & Normal \\
\hline 10457 & Luvissolo Crômico & Cultivo de alho irrigado (comercial) & Pres ente & Normal \\
\hline 10458 & Vert issolo Hid romórfico & Pastagem nativa (Caatinga Arbustiva fechada) & Ausente & Normal \\
\hline 10459 & Neossolo Litólico & Pastagem nativa (Caatinga arbustiva fechada) & Ausente & Normal \\
\hline 10460 & Vert issolo Hid romórfico & Pastagem nativa (C aatinga Arbu stiva aberta) & Pres ente & Normal \\
\hline 10461 & Neossolo Flúvico & Capim irrigado & Pres ente & Normal \\
\hline 10462 & Neossolo Flúvico & Fruticultura irriga da (comercial) & Pres ente & Normal \\
\hline
\end{tabular}

Ainda em relação a essas observações, Leprun et al. (1995) também ressaltam que, no semi-árido nordestino, comparando as áreas de vegetação preservada com as que apresentam cobertura vegetal degradada e solo exposto, a porcentagem média do escoamento superficial aumenta de $3-5 \%$ para 20 $30 \%$, o que faz com que os açudes sejam alimentados por águas mais ricas em sais.

Pelo que acabamos de expor, embora de pouca expressão no conjunto dessas terras, os exemplos citados na literatura consultada sobre salinização nos solos dominantes nessa região, adicionado dos resultados obtidos nesse trabalho através das análises laboratoriais, serve como um alerta para projetos que visem o aumento da área irrigada no Cariri.

Quanto a fertilidade, os padrões analisados foram considerados normais para todos os tipos de solos coletados, inclusive aqueles nos quais as caatingas encontravam-se submetidas a forte degradação e onde, por esse último parâmetro, estaríamos numa situação de avançado estágio de desertificação (amostras 9142, 10455 e 10460).

Essa é uma constatação, em princípio, contraditória, uma vez que normalmente associamos a diminuição da cobertura vegetal ao aumento da erosão e, consequentemente, a queda na fertilidade natural do solo, o que também entra em choque com o que se convenciona esperar de uma área desertificada.

Os resultados encontrados em relação a fertilidade dos solos do Cariri também se contrapõem, em princípio, com as pesquisas até agora desenvolvidas sobre erosividade da chuva e perda de sedimentos na região. Nesse caso, a erosividade é entendida como uma conseqüência da intensidade e duração da precipitação e da massa, do diâmetro e da velocidade da gota da chuva, influenciando diretamente o escoamento superficial e o desgaste dos solos . Logo, é um parâmetro importante para se calcular a influência desses elementos na fertilidade dos solos.

Para os poucos trabalhos que até agora se propuseram a realizar esse cálculo para o Cariri (Albuquerque et al., 2002 e 2005; Silva et al., 2006), os resultados apresentaram elevado potencial de perda de sedimentos nas áreas desmatadas. Logo, teoricamente, esses dados deveriam estar influenciando diretamente a fertilidade dos solos da região, o que não correspondeu ao que foi constatado nos resultados das análises efetuadas. 
Como nas fórmulas desenvolvidas para calcular esse parâmetro são levadas em conta apenas as questões inerentes as características da pluviosidade, consideramos que, para as condições pedológicas do Cariri, a identificação da erosividade, por si só, não é suficiente para apontarmos as prováveis conseqüências para o quadro de fertilidade dos solos da região em virtude da ocorrência dos processos de desgaste passíveis de ocorrerem. Nesse caso, o cálculo da erodibilidade, por levar em consideração as características intrínsecas do solo frente aos processos erosivos, adicionado ao parâmetro erosividade, daria uma resposta mais segura a essa questão.

É sabido que em áreas onde a pecuária é dominante, como é o caso do Cariri, em comparação com a agricultura, os efeitos dessa primeira atividade no tocante as alterações possíveis de ocorrerem na fertilidade do solo, são menores. Entretanto, reconhecemos que a elevada pedregosidade (calhaus e matacões) encontrada nos solos dessa região oferece uma resposta mais efetiva a essa questão.

O Pavimento Desértico (cobertura detrítica dominante por sobre quase todos os tipos de solos do Cariri), exerce uma função importante em relação a proteção da camada superficial dos solos quanto aos efeitos erosivos, notadamente os que são desencadeados pelos eventos chuvosos e o conseqüente escoamento em lençol, contribuindo assim decisivamente para a manutenção da sua fertilidade, mesmo sob situação de extrema pobreza de cobertura vegetal. Essa mesma característica e os seus efeitos foram observados por diversos autores em experimentos nessa e em outras áreas do semi-árido (Silva et al., 1986; Albuquerque et al. 2004; Sales \& Oliveira, 2006).

A partir das observações no campo, a professora Dirce Suertegaray, da Universidade Federal do Rio Grande do Sul (informação pessoal) levanta a possibilidade de que este Pavimento Desértico no Cariri seja na realidade um paleopavimento localizado entre dois solos de idades distintas, sendo o mais superficial, o de origem mais recente. Delimitando esses dois tipos de solos teríamos, originalmente, o Pavimento Desértico. Durante a estação chuvosa, através do escoamento superficial, o material fino erodido das vertentes seria depositado nas várzeas que se encontram bastante assoreadas na região, processo que faz com que a camada pedregosa aflore cada vez mais em superfície, situação com a qual nos deparamos mais comumente.

Essas observações, por sua vez, encontram respaldo na ocorrência dos eventos paleoclimáticos pelos quais passaram a atual zona semi-árida nordestina, onde vigoraram inclusive condições de clima até mais seco que o atual, responsáveis, por exemplo, pelo surgimento dos inselbergs disseminados por essa região, interrompidas por condições de clima mais úmido (Ab'Sáber, 1969, 1974, 1977; Bigarella et al., 1975; Tricart, 1959). Assim, na primeira situação, sob o domínio do intemperismo físico, do ponto de vista da cobertura superficial dos solos ocorreria a formação de sedimentos mais grosseiros, formando o Pavimento Desértico. Na segunda situação, sob o domínio do intemperismo químico, seriam formados os sedimentos de granulação mais fina, recobrindo a camada pedregosa.

A referida dinâmica climática e as suas conseqüências pedológicas foram destacadas no trabalho de Lustosa (2004), no município de Irauçuba (CE), onde foi observada a presença de nódulos ferruginosos em alguns horizontes internos de solos, originados durante o predomínio de um clima mais úmido que o atualmente dominante, estando o mesmo recoberto superficialmente por um material arenoso, mais condizente com a situação semi-árida presente no momento.

Conforme já comentamos anteriormente, questões relacionadas a erodibilidade dos solos existentes no Cariri e a sua relação com a fertilidade devem ser mais e melhor estudadas. Neste sentido, Leprun (1983) fornece dados importantes para solucionar essa questão. Nesse último trabalho citado, o referido pesquisador realizou in situ o exame microscópico de lâminas delgadas da superfície dos solos de diversas áreas do semi-árido nordestino, antes e depois da chuva, com o objetivo de identificar o modo de reunião dos agregados, a junção dos aglomerados microscópicos, a dispersão e perturbação dos mesmos, para entender e explicar o mecanismo mais íntimo dos processos de erosão.

Os resultados encontrados apontaram a presença de forte resistência dos agregados à destruição pela água no horizonte superficial dos solos com elevado percentual de argila de alta atividade coloidal (montmoriloníticas), tais como o Luvissolo Crômico (presentes em 42,7\% do Cariri), o Vertissolo 
Hidromórfico (8,9\% do Cariri), o Planossolo Nátrico e Háplico(3,1\% do Cariri) e o Chernossolo Rêndzico (0,2\% do Cariri). Além desses, com as mesmas características, Leprun (1983) destaca os solos cauliníticos que, dentre os pesquisados, encontra-se no Cariri o Luvissolo Hipocrômico (1,2\% da região).

Essa pesquisa demonstrou que os agregados dos horizontes desses solos, mesmo sofrendo acentuado arrastamento ou transporte pela água, não são destruídos. Isso implica que a sua fertilidade natural não é afetada por esses processos. Dessa forma, podemos explicar os resultados encontrados quanto a não alteração da fertilidade dos solos analisados no Cariri, mesmo nas áreas onde ocorreu forte degradação das caatingas.

Noutras pesquisas relacionadas a erosão e seus efeitos nos solos desenvolvidas por Leprun (1981, 1988 e 1989) no Sahel e em parte do semi-árido nordestino, incluindo-se aí alguns municípios do Cariri paraibano, são expostos alguns resultados que explicam e justificam ainda mais os dados obtidos nesse trabalho. Nesse caso, as pesquisas desse autor revelaram que:

1) Os índices de erosividade das chuvas no Sahel são bem mais elevados que no semi-árido nordestino;

2) Os regimes pluviométricos e térmicos da zona semi-árida nordestina determinam condições menos agressivas que no Sahel, sendo, portanto, mais favoráveis a boa conservação dos solos e da água;

3) Os solos nordestinos são mais argilosos, situados próximos da rocha-mãe, (o que lhes garante elevada riqueza em minerais alteráveis) e, em geral, não tendem à formação de crostas superficiais. Dessa forma, são mais resistentes a erosão hídrica.

O trabalho de Sousa (2006), desenvolvido no município de São João do Cariri (Cariri paraibano), também fornece elementos importantes que podem ser acrescidos aos que estamos discutindo. Nesse caso, ao analisar diversas amostras de solos do tipo Luvissolo Crômico e Vertissolo Cromado, coletadas em situações diferenciadas de vegetação (arbórea, subarbórea, arbustiva, subarbustiva e sob a presença de algaroba - Prosopis juliflora) e graus de cobertura vegetal (rala, aberta e densa), não identificou efeitos nessas condições que pudessem ser modificadoras da fertilidade natural, embora tenha detectado maior presença de Bases nas áreas sob cobertura vegetal densa.

Por tudo o que expusemos, os resultados apresentados em relação a vegetação e aos solos da região do Cariri mostraram situações diferenciadas no que diz respeito a sua degradação, tornando ainda mais complexos os estudos sobre o processo de desertificação e as diversas maneiras como este pode se manifestar.

\section{Considerações Finais}

Com base no fato de que não foram identificadas alterações na fertilidade dos solos da área de estudo, poderíamos dizer inicialmente que, a despeito da degradação da vegetação, a recomposição da mesma ocorreria de forma natural, tão logo fosse cessado ou diminuído o uso dessas terras. Esse aspecto é inclusive previsto em pesquisas onde se demonstra a existência de capacidade de regeneração da caatinga numa sequência média de 1 a 3 anos para o estádio herbáceo, 10 a 15 anos para o estádio arbustivo, acima de 15 a 25 anos para o estádio arbustivo-arbóreo e acima de 25 anos para o estádio arbóreo-arbustivo (Araújo Filho \& Carvalho, 1997).

Entretanto, não podemos fazer disso uma regra geral para todo o Cariri, uma vez que nessa região os padrões de vegetação são extremamente diversificados, não apenas por razões naturais, mas também ao se levar em consideração as intervenções seculares que as atividades humanas têm exercido nas caatingas existentes em seu território.

Também poderíamos pensar que a recuperação das áreas desertificadas nessa região, a partir da retirada parcial ou total de qualquer tipo de uso existente nas terras degradadas, seria, em princípio, uma 
tarefa de fácil execução. Entretanto, o predomínio de uma estrutura fundiária dominada pela pequena propriedade, portanto de uso intensivo dos solos, associada às formas como essas terras vêm sendo utilizadas e os baixos níveis sócio-econômicos existentes, ao mesmo tempo em que desencadeiam parte desse tipo de degradação, tornam qualquer ação de contenção desse processo de elevada complexidade.

Sobre o que foi acima relatado, cabe mais uma vez chamar atenção para as observações de Leprun (1995) em relação ao semi-árido nordestino. Os estudos desse autor indicam que a ocorrência de secas acentuadas, particularmente nas áreas onde os solos apresentam pequena profundidade, como é o caso de grande parte do Cariri paraibano, acaba criando uma situação em que a infiltração e o estoque da água utilizada pelas plantas vai diminuindo de forma intensa, o que faz disso um importante fator limitante para a recolonização dessas áreas pela vegetação. Tais observações foram constatadas por Silva (2003b) para a região em estudo, calculando o balanço hídrico ao longo de 20 anos.

Ressaltamos ainda que a retirada de grande parte da cobertura vegetal submete os solos a uma amplitude térmica maior, elevando no período diurno as taxas de evapotranspiração e afetando todos os ecossistemas existentes. Levando em consideração esse aspecto e devido ao uso do solo que existe nessas terras, acabam resistindo somente espécies de plantas que sejam ainda mais tolerantes a temperaturas mais elevadas que aquelas anteriormente dominantes e a seca edáfica, como vem demonstrando pesquisas recentes baseadas na aplicação de modelos climáticos para o semi-árido nordestino (Oyama, 2002; Nobre et al., 2005; Souza, 2006).

Especificamente para o Cariri, os estudos de Silans et al. (2001a, 2001b, 2002a, 2002b e 2003) tem demonstrado que a retirada parcial ou total da vegetação que vem se processando nessa região, acaba exercendo forte influência do ponto de vista pedológico e bioclimático. Esta situação acaba desfavorecendo a presença de espécies das caatingas mais exigentes em água, dos tipos arbóreos e mais adensados dessa formação, substituídos, cada vez mais, por pequenas "ilhas de vegetação", o que pode ser considerado uma estratégia das plantas sobreviventes a um ambiente cada vez mais inóspito (Goldfarb, 2006), logo, de difícil recuperação espontânea.

Portanto, para além das soluções técnicas direcionadas exclusivamente a esse problema, o combate à desertificação no Cariri exige o repensar dessa região e, por extensão, de todo o semi-árido brasileiro, como um espaço multidimensional, onde as questões naturais, sociais, culturais, políticas e de produção estão intrinsecamente relacionadas. Logo, qualquer medida empreendida, para obter resultados positivos e sustentáveis, tem que levar em consideração esses elementos de forma integrada.

\section{Referência Bibliográfica}

AB'SABER, A. N. Participação das superfícies aplainadas nas paisagens do Nordeste brasileiro. Geomorfologia, n 19. São Paulo: IGEOG-USP, 1969.

O Domínio Morfoclimático das caatingas brasileiras. São Paulo: USP/IGEUG, Geomorfologia, $\mathrm{n}^{\circ}$ 43, 1974.

Problemática da desertificação e da savanização no Brasil intertropical. São Paulo: USP/IGEUG, Geomorfologia, $\mathrm{n}^{\circ}$ 53, 1977.

AguiAR, W. \& RIBEIRO COUTINHO, M. O. Elias Herckmans. Descrição Geral da Capitania da Paraíba. João Pessoa: A União, 1982.

ALBUQUERQUE, A. W.; FILHO, G. M.; SANTOS, J. R.; COSTA, J. P. V.; SOUZA, J. L. Determinação de fatores da equação universal de perda de solo em Sumé, PB. Campina Grande: Revista Brasileira de Engenharia Agrícola e Ambiental, v. 9, nº 2, 2005, p. 153-160.

ALBUQUERQUE, A. W.; LOMBARDI NETO, F.; SRINIVASAN, V. S.; SANTOS, J. R. manejo da cobertura do solo e práticas conservacionistas nas perdas de solo e água em Sumé, PB. Campina Grande: Revista Brasileira de Engenharia Agrícola e Ambiental, v. 6, nº 1, 2002, p. 136-141.

ALBUQUERQUE, S. G.; SOARES, J. G. G.; GUIMARÃES FILHO, C.; OLIVEIRA, M. C. Dinâmica do estrato herbáceo de uma vegetação de caatinga do sertão pernambucano, sob intensidades de uso 
por caprinos. Petrolina: Embrapa, 2004. Disponível em <www.cpatsa.embrapa.br>. Acesso 04 jan. 2007. ALMEIDA, E. História de Campina Grande. $2^{\mathrm{a}}$ ed. João Pessoa: Ed. Universitária da UFPB, 1979.

ANDRADE, K. S.; FEITOSA, P. H. C.; BARBOSA, M. P. Sensoriamento Remoto e SIG na identificação de áreas em processo de desertificação no município de Serra Branca - PB: estudo de caso. XIII Simpósio Brasileiro de Sensoriamento Remoto. Florianópolis: INPE, 21-26 abr. 2007, p. 4351-4356. Disponível em $<$ http://www.inpe.br/biblioteca/>. Acesso 03 ago. 2007.

ARAÚJO FILHO, J. A. \& CARVALHO, F. C. Desenvolvimento sustentado da caatinga. Sobral: Embrapa, Circular Técnica, nº 13, 1997.

BIGARELLA, J. J.; ANDRADE-LIMA, D.; RIEHS, P. J. Considerações a respeito das mudanças paleoambientais na distribuição de algumas espécies vegetais e animais no Brasil. Simpósio Internacional sobre o Quaternário. Anais da Academia Brasileira de Ciências, vol. 47 (suplemento). Curitiba-Porto Alegre: Academia Brasileira de Ciências, 1975, p. 411-464.

BRASIL. Levantamento Exploratório-Reconhecimento de Solos do Estado da Paraíba. Rio de Janeiro: Ministério da Agricultura/Sudene, 1972.

BRASIL. Projeto RADAMBRASIL. Levantamento de Recursos Naturais. Folha SB. 24/25 Jaguaribe/ Natal, v. 23. Rio de Janeiro: Ministério das Minas e Energia, 1981.

CARVAlho, M. G. R. F. Estado da Paraíba. Classificação Geomorfológica. João Pessoa: UFPB/Ed. Universitária, 1982.

CONTI, J. B. Desertificação nos trópicos: proposta de metodologia de estudo aplicada ao Nordeste brasileiro. 271 f. Tese de Livre-Docência (Programa de Pós-Graduação em Geografia) - USP, São Paulo, 1995.

CONVENÇÃO DAS NAÇÕES UNIDAS DE COMBATE À DESERTIFICAÇÃO. Tradução: Delegação de Portugal. Lisboa: Instituto de Promoção Ambiental, 1995.

DUQUE, J. G. O Nordeste e as plantas xerófilas. Mossoró: ESAM/Fundação Guimarães Duque, 1980. EMBRAPA. Sistema Brasileiro de Classificação de Solos. 2a ed. Rio de Janeiro: Embrapa Solos, 2006. FERREIRA, L. F. G. Raízes da indústria da seca. O caso da Paraíba. João Pessoa: Ed. Universitária da UFPB, 1993.

GOLDFARB, M. C. Contribuição da vegetação tipo caatinga nos processos de transferência de calor e massa no complexo solo-vegetação-atmosfera na região semi-árida de São João do Cariri. 124 f. Tese (Doutorado em Engenharia Mecânica) - UFPB, João Pessoa, 2006.

GOMES DA SILVA, G. A problemática da desertificação no ecossistema da caatinga do município de São João do Cariri. 93 f. Monografia (Especialização em Desertificação) - UFPI, Teresina, 1993.

LEPRUN, J. C. A erosão, a conservação e o manejo do solo no Nordeste brasileiro. Recife: Sudene, 1981.

Manejo e conservação de solos do Nordeste. Recife: Sudene, 1988.

Etude comparée dês facteurs de l'érosion dans Le Nordeste du Brésil et en Afrique de l'Ouest. BRET, B. (Coord.). Les hommes face aux sécheresses. Paris: IHEAL \& EST, 1989, p. 139-154.

LEPRUN, J. C.; MOLINIER, M.; CADIER, E.; FOTIUS, G.; GALINDO, O. Les sécheresses de La région Nordeste du Brésil et leurs conséquences. Secheresse. Paris: Jonh Libbey/Eurotext, 1995, 6: 23-33.

LUSTOSA, J. P. G. Caracterização morfológica, micromorfológica e mineralógica de três topossequências no município de Irauçuba-CE e suas relações com o processo de desertificação. 162 f. Tese (Doutorado em Geociências) - UNESP, Rio Claro, 2004.

MAINGUET, M. L'homme et la sécheresse. Paris: Masson, Collection Géographie, 1995.

MELlO NETO, J. A. G. Manuel Arruda Câmara: obras reunidas. Recife: Fundação de Cultura da Cidade do Recife, 1982.

MENEZES, R. S. C. \& SAMPAIO, E. V. S. B. Agricultura sustentável no semi-árido nordestino. OLIVEIRA, T. S.; ASSIS JR., R. N.; ROMERO, R. E.; SILVA, J. R. C. (Edit.). Agricultura, sustentabilidade e o semi-árido. Fortaleza: UFC/SBCS, 2000, p. 20-46. 
MOURA, C. S. Vulnerabilidade das terras agrícolas, degradação ambiental e riscos a desastres ENOS no município de Sumé. 132 f. Dissertação (Mestrado em Engenharia Agrícola) - UFCG, Campina Grande, 2002.

NANTES, M. Relação de uma missão no rio São Francisco. Tradução e comentários Barbosa Lima Sobrinho. $2^{\mathrm{a}}$ ed. São Paulo: Companhia Editora Nacional, Coleção Brasiliana, v. 368, 1979.

NIMER, E. Pluviometria e recursos hídricos de Pernambuco e Paraíba. Rio de Janeiro: IBGE/SUPREN, 1979. 1988, p. 7-39.

. Desertificação: realidade ou mito? Revista Brasileira de Geografia, 50 (1). Rio de Janeiro: IBGE,

NOBRE, C.; ASSAD, E. D.; OYAMA, M. D. Mudança ambiental no Brasil. Scientific American Brasil. São Paulo: Ediouro/Segmento-Duetto Editorial Ltda., 2005, p. 70-75.

OYAMA, M. D. Conseqüências climáticas da mudança de vegetação do Nordeste brasileiro: um estudo de modelagem. 220 f. Tese (Doutorado em Meteorologia) - INPE, São José dos Campos, 2002.

PALMIERI, F. \& LARACH, J. O. I. Pedologia e Geomorfologia. GUERRA, A. J. T. \& CUNHA, S. B. (Orgs.). Geomorfologia e Meio Ambiente. Rio de Janeiro: Bertrand-Brasil, 1996, p. 59-122.

PARAÍBA. Plano Diretor de Recursos Hídricos do Estado da Paraíba (PDRH-PB). Síntese do estudo de reconhecimento de solos em meio digital do Estado da Paraíba. João Pessoa: SEPLAN, 1997.

PEREIRA, D. D. Quando as Políticas Públicas auxiliam o processo de desertificação: o caso do Cariri paraibano. MOREIRA, E. (Org.). Agricultura familiar e desertificação. João Pessoa: UFPB/Ed. Universitária, 2006, p. 179-203.

PINTO, I. F. Datas e notas para a História da Paraíba. V. 1. João Pessoa: Ed. Universitária da UFPB, 1977.

QUIRINO, Z. G. M. Fenologia, síndromes de polinização e dispersão e recursos florais de uma comunidade de caatinga no Cariri paraibano. 117 f. Tese (Doutorado em Biologia Vegetal) - UFPE, Recife, 2006.

ROXO, M. J. O panorama mundial da desertificação. MOREIRA, E. (Org.). Agricultura Familiar e Desertificação. João Pessoa: Ed. Universitária da UFPB, 2006, p. 11-32.

SALES, M. C. L. \& OLIVEIRA, J. G. B. Análise da degradação ambiental no núcleo de desertificação de Irauçuba. SILVA, J. B.; DANTAS, E. W. C.; ZANELLA, M. E.; MEIRELES, A. J. A. (Orgs.). Litoral e Sertão: natureza e sociedade no Nordeste brasileiro. Fortaleza: Expressão Gráfica, 2006, p. 223-232.

SAMPAIO, E. V. S. B. Overview of the Brazilian caatinga. BULLOCK, S. H.; MOONEY, H. A.; MEDINA, E. (Edit.). Seasonal dry tropical forests. Cambridge: Cambridge UniversitY Press, 1995.

SILANS, A. M. B. P.; SILVA, F. M.; RODRIGUES, A. A.; MARINHO, L. S. Estudo experimental do comportamento térmico do solo em uma região coberta por vegetação tipo caatinga no estado da Paraíba. XII Congresso Brasileiro de Agrometeorologia. Fortaleza, 2001a (CD-ROM).

SILANS, A. M. B. P.; WERLANG, L. M. SILVA, F. M. Estudo experimental da interceptação da chuva pela vegetação de caatinga. XIV Simpósio Brasileiro de Recursos Hídricos e V Simpósio de Hidráulica e Recursos Hídricos dos Países de Língua Oficial Portuguesa. Aracaju, 2001b (CD-ROM).

SILANS, A. M. B. P.; AlENCAR, R. I. S.; SILVA, F. M.; COSTA, A. M. B.; BARBOSA, F. A. R. Comportamento dos fluxos térmicos na interface entre a camada de rugosidade e a subcamada limite atmosférica sobre uma região de caatinga/PB. VI Simpósio de Recursos Hídricos do Nordeste. Maceió, 2002a (CD-ROM).

SILANS, A. M. B. P.; WERLANG, L. M. SILVA, F. M. Estudo experimental do comportamento térmico do solo em uma região coberta por vegetação tipo caatinga, no estado da Paraíba. XII Congresso de Meteorologia. Foz do Iguaçu, 2002b (CD-ROM).

SILANS, A. M. B. P.; SILVA, F. M. Bilans energétique et hydrique en une region semi-aride dominée par la caatinga. Proceedings of the Conférence Internationale: Hidrologie dês régions méditerranéennes et semi-arides. Montpellier: 01-04 abr. 2003.

SILVA, F. M. Estudo teórico-experimental dos balanços energético e hídrico no complexo solo- 
vegetação-atmosfera em região de caatinga. 215 f. Tese (Doutorado em Engenharia Mecânica) - UFPB, João Pessoa, 2003a.

SILVA, J. H. Impacto ambiental causado pelo déficit hídrico no processo de degradação ambiental da microrregião do Cariri paraibano. 112 f. Dissertação (Mestrado em Desenvolvimento e Meio Ambiente/ PRODEMA) - UEPB, Campina Grande, 2003b.

SILVA, I. F.; CAMPOS FILHO, O. R.; ANDRADE, A. P. Erodibilidade de seis solos do semi-árido paraibano obtida com chuva simulada e método nomográfico. Revista Brasileira de Ciência do Solo, v. 10. Campinas: RBCS, 1986, p. 283-287.

SILVA, R. M.; CAMPOS, S. M. F.; SANTOS, C. A. G. Erosividade da chuva e desertificação no semi-árido paraibano. MOREIRA, E. (Org.). Agricultura familiar e desertificação. João Pessoa: Ed. Universitária/ UFPB, 2006, p. 291-300.

SOUSA, S. M. S. C. Relações entre vegetação, relevo, fertilidade do solo e matéria orgânica em bacia hidrográfica de região semi-árida. $64 \mathrm{f}$. Dissertação (Mestrado em Manejo de Solo e Água) UFPB, Areia, 2006.

SOUSA, R. F. Terras agrícolas e o processo de desertificação em municípios do semi-árido paraibano. 180 f. Tese (Doutorado em Engenharia Agrícola) - UFCG, Campina Grande, 2007.

SOUZA, B. I. Contribuição ao estudo da desertificação na bacia do Taperoá-PB. 120 p. Dissertação de Mestrado. PRODEMA-UFPB, João Pessoa, 1999.

SOUZA, S. S. Impactos climáticos regionais da mudança de vegetação no semi-árido do Nordeste brasileiro. 211 f. Tese (Doutorado em Meteorologia) - INPE, São José dos Campos, 2006.

SOUZA, B. I. Cariri paraibano: do silêncio do lugar à desertificação. 198 f. Tese (Doutorado em Geografia) - UFRGS, Porto Alegre, 2008.

SOUZA, B. I. \& SUERTEGARAY, D. M. A. Contribuição ao debate sobre a transposição do rio São Francisco e as prováveis conseqüências em relação a desertificação nos Cariris Velhos (PB). Terra Livre, ano 21, v. 2, nº. 25. Goiânia: AGB, jul-dez/2005, p. 139-155.

SOUZA, B. I. \& SUERTEGARAY, D. M. A. Estratégias de sobrevivência do pequeno produtor em áreas sujeitas à desertificação. Seminário Luso-brasileiro-caboverdiano: Agricultura familiar em regiões com riscos de desertificação. João Pessoa: UFPB, 2006.

SOUZA, B. I. \& LIMA, E. R. V. Cartografia da desertificação no Cariri paraibano. VII Encontro Nacional da ANPEGE. Niterói: ANPEGE/UFF, 2007.

TAVARES DE MELO, S. Desertificação: etimologia, conceitos, causas e indicadores. Revista da UNIPÊ 2 (2). João Pessoa: UNIPÊ, 1998, p.19-33.

TRICART, J. As Zonas Morfoclimáticas do Nordeste Brasileiro. Salvador: Laboratório de Geomorfologia e Estudos Regionais/UFBA, 6(4), 1959.

Trabalho enviado em março de 2009

Trabalho aceito em agosto de 2009 